\title{
The relations between the patterns of gas exchange and water loss in diapausing pupae of large white butterfly Pieris brassicae (Lepidoptera: Pieridae)
}

\author{
Katrin JÕGAR, Aare KUUSIK, Luule METSPALU, Külli HIIESAAR, AnNe LUIK, Marika MÄND \\ and ANTS-JOHANNES MARTIN
}

Institute of Plant Protection, Estonian Agricultural University, Kreutzwaldi 64, 51014 Tartu, Estonia; e-mail: katrinj@eau.ee

Key words. Pieris brassicae, diapause, gas exchange cycles, water loss, body movements

\begin{abstract}
The relations between the patterns of discontinuous gas exchange cycles (DGCs) and water loss were investigated in nonchilled diapausing pupae of the white cabbage butterfly Pieris brassicae kept at room temperature $\left(22-24^{\circ} \mathrm{C}\right)$ in Petri dishes. An electrolytic respirometer, combined with an infrared (IR) actographic device was used for the simultaneous recordings of metabolic rate, cyclic release of carbon dioxide (bursts), passive suction inspirations (PSIs) and body movements. The patterns of cyclic gas exchange in four- and five-month-old non-chilled diapausing pupae varied individually to a considerable extent. About $40 \%$ of the pupae displayed long DGCs lasting 1-3 h, while the interburst periods were characterised by rare and almost regular large PSIs succeeding at intervals of 1-4 min. Nearly $30 \%$ of the pupae exhibited short DGCs lasting 3-5 min, while between the bursts there occurred unclear frequent gas exchange microcycles. Standard metabolic rate (SMR) did not reveal significant differences between long DGCs and short DGCs ranging from 32-56 (mean 47.6 \pm 4.6 ) $\mathrm{ml} \mathrm{O}_{2} \mathrm{~g}^{-1} \mathrm{~h}^{-1}$, and 28-61 (mean $44.95 \pm 5.3$ ) $\mathrm{ml} \mathrm{O}_{2} \mathrm{~g}^{-1} \mathrm{~h}^{-1}$, respectively. The mentioned levels of SMR were characteristic of diapausing pupae.

Water loss in pupae with long DGCs was determined gravimetrically to be $0.29 \pm 0.1 \mathrm{mg} \mathrm{g}^{-1} \mathrm{day}^{1}$. At the same time, water loss in pupae that showed only short DGCs and irregular microcycles was $1.73 \pm 0.31 \mathrm{mg} \mathrm{g}^{-1}$ day $^{-1}$, which was significantly higher than in individuals characterised by long DGCs. We suggest that water loss in the non-chilled diapausing pupae may depend significantly on the patterns of cyclic gas exchange: long cycles and rare but deep PSIs exerted a marked water conserving effect.
\end{abstract}

\section{INTRODUCTION}

The discontinuous pattern of gas exchange, i.e. cyclic release of carbon dioxide (burst) and often also cyclic uptake of oxygen into the tracheae, termed as the discontinuous gas exchange cycle (DGC) has been described in different developmental stages of many insects. The DGC is usually divided into three phases according to the spiracular behaviour: closed $(\mathrm{C})$, flutter $(\mathrm{F})$, and open $(\mathrm{O})$ or burst (B) (see Miller, 1974, 1981; Kestler, 1985; Mill, 1985; Lighton, 1994;). Cyclic gas exchange is characterised by a precise control of the spiracles, allowing development of negative pressure in the tracheae with small amounts of air being periodically inspired. This pattern is known as passive suction ventilation (PSV) also referred to as diffusive-convective gas exchange. However, the term passive suction inspiration (PSI) used by Slama (1988), Slama \& Neven (2001), and Slama \& Miller (2001), seems to be more correct for denoting the gas exchange microcycles, as the term "ventilation" associates with muscular activity and active ventilation.

The DGC is often regarded as a mechanism for minimising respiratory water loss, especially in the pupal stage where, due to the hard integument, cuticular water loss is assumed to form a smaller fraction of total water loss (see Hadley, 1994b, for review). However, it is not easy to prove experimentally the "water conserving theory" of cyclic gas exchange in insects. It has not been experimentally verified that intermittent release of $\mathrm{CO}_{2}$ in lepidopteran pupae results in overall saving of water from that which would be lost during a more regulated pattern of spiracular opening and closing (Hadley, 1994b).

There exist data supporting the "water conserving theory" as well as data refuting it. For example, some experiments with hydrated and dehydrated adult grasshoppers do no support the assumption that the DGC is an adaptation for reducing water loss (Hadley \& Quinlan, 1993). On the other hand, Duncan et al. (2002) demonstrated that the gas exchange pattern in tenebrionid beetle, Pimelia grandis, depended on the state of hydration: dehydrated beetles displayed DGCs, while beetles that were provided food and water showed continuous respiration. Moreover, several other factors are likely to influence the gas exchange pattern (Chown, 2002). ). It is possible that the DGC plays different adaptive role depending on insect species and the environment. In the underground habitats the DGC in adult insects may be an adaptation to hypoxic and hypercapnic environments (Lighton, 1998).

Passive suction ventilation was thought to be a widely distributed mechanism for water retention from the tracheae (Kestler, 1980; 1982, 1985). Kestler (1985) and Machin et al. (1991) registered increased water loss during the burst of carbon dioxide compared with the period of "constriction-flutter" (CF) in the cockroach Periplaneta americana.

The diapausing pupae of Pieris brassicae seemed to be favourable for studying the relationship between water loss and the gas exchange patterns in lepidopteran pupae. First, in the pupal stage it is easy to measure actual standard metabolic rate, i.e. the metabolic rate in an insect 
that is inactive, not digesting a meal and not subjected to any stress (see Withers, 1992). Second, there exist lepidopteran species in which patterns of gas exchange vary individually from discontinuous to continuous. In developing pupae of Galleria mellonella, water loss did not differ between the non-cyclic and the cyclic individuals in one and the same population (Kuusik et al., 1999). G. mellonella is normally characterised by short cycles of discontinuous gas exchange (Kuusik et al., 1994; Slama, 1999, 2000).

Our preliminary observations and those of others (Harak et al., 1999; Tartes et al., 2002) showed that nonchilled diapausing pupae of Pieris brassicae exhibited essentially varying individual patterns of gas exchange if they were kept at room temperatures for 4-5 months after pupation.

At present time, DGCs are often studied by means of the flow-through respirometry (IR gas analysers) which does not enable the direct recording of discrete passive suction inspirations (PSIs) and movements due to muscular ventilation. Slama $(1988,1999)$ elaborated specific methods for the simultaneous recording of muscular ventilation, oxygen consumption and PSIs. Metabolic rates, gas exchange cycles, including PSIs, and active body movements were recorded in parallel also by Kuusik et al. (1994, 2001) and Tartes et al. (2002) using several combined techniques.

According to some earlier investigations, non-chilled pupae of $P$. brassicae displayed during the first two months of diapause intermittent $\mathrm{CO}_{2}$ bursts, occurring at different levels (large, intermediate and microbursts), while the interburst periods between the large bursts lasted 10 to 26 h (Harak et al., 1999; Tartes et al., 2002). Adult development can be initiated in diapausing pupae of $P$. brassicae only after exposure to cold (about $5^{\circ} \mathrm{C}$ ) for 2-3 weeks (chilling) and SMR in developing pupae increases over $200 \mathrm{ml} \mathrm{O}_{2} \mathrm{~g}^{-1} \mathrm{~h}^{-1}$ (Harak et al., 1999). The pattern of gas exchange and body mass loss have not been studied in non-chilled pupae kept at room temperatures $\left(20-22^{\circ} \mathrm{C}\right)$ in the state of "permanent" diapause for several months.

One of the aims of the present paper was to study the relationship between the gas exchange patterns and body mass loss in non-chilled diapausing pupae of $P$. brassicae kept at room temperatures. The second purpose was to observe active body movements during bursts and the patterns of gas exchange microcycles during interburst periods by means of an electrolytic respirometer allowing a direct recording of PSIs.

\section{MATERIAL AND METHODS}

The eggs of $P$. brassicae were collected in a cabbage field near Tartu (Estonia). The insects were reared in laboratory in short-day conditions $\left(12 \mathrm{~L}: 12 \mathrm{D}\right.$, at $\left.20-22^{\circ} \mathrm{C}\right)$. The non-chilled pupae were kept in the state of "permanent" diapause during the winter months at room temperature $\left(20-22^{\circ} \mathrm{C}\right)$ and air humidity of $50-65 \%$ RH in Petri dishes. Experiments were undertaken in December and January when the insects had spent 4-5 months in diapause.
The electrolytic differential microrespirometer (referred to below as the respirometer) used was described in detail earlier (Tartes \& Kuusik, 1994; Kuusik et al., 1996; Tartes et al., 1999). Eppendorf tubes $(1.5 \mathrm{ml})$ were used as exchangeable insect chambers. The chamber was connected with a vessel containing $15 \% \mathrm{KOH}$ solution as an absorbent of $\mathrm{CO}_{2}$ causing about 90\% RH above the solution (Kozhanchikov, 1961). The graphs indicated the arbitrary units " $\mathrm{FO}_{2}\left(\mathrm{ml} \mathrm{h}^{-1}\right)$ " corresponding to the rate of oxygen production by electrolysis. In principle, this design ensures continuous replacement of consumed oxygen by electrolytically produced oxygen. Rapid changes in the pressure in the insect chamber, caused by insect body movement or other rapid events, are not compensated and will lead to corresponding changes in the registration current reflected as peaks on recordings.

Data were acquired with a DAS 1401 A/D board (Keithley, Metrabyte) with a $10-\mathrm{Hz}$ sampling rate. Mean metabolic rate was automatically calculated by statistical program by averaging the data over periods involving at least 3 long DGCs or 20 short ones. The bursts of carbon dioxide were indirectly recorded on the respirograms, as during carbon dioxide burst electrolysis current and oxygen generation decreased causing downward peaks for several minutes. Amounts of released carbon dioxide were not calculated. The upward spikes lasting 0.1-0.3 sec were due to rapid air intakes into the tracheae, or to passive suction inspirations (PSIs). The PSI spikes were not calibrated.

The respirometer was combined with an infrared (IR) optical device usually referred to as the insect IR cardiograph (Hetz, 1994; Wasserthal, 1996; Hetz et al., 1999; Kuusik et al., 2001; Metspalu et al., 2001, 2002). Two IR-emitting diodes (TSA6203) were placed on one side of the insect chamber, and two IR sensor diodes (BP104) were placed on the opposite side of the chamber. We used this IR-optical device mainly for detecting ventilatory movements such as abdominal pulsations and vigorous swinging movements; heartbeats were recorded as well.

All measurements were made in an incubator at $22^{\circ} \mathrm{C}$. The insects were weighed before and after the experiments by means of an analytical balance to the nearest $0.1 \mathrm{mg}$. The gravimetric method of measuring transpiration assumes that body mass loss and water loss are equivalent in the pupal stage (Hadley, 1994a).

The means were compared using Student's t-test. The level of significance for all tests was $\mathrm{P}<0.05$.

\section{RESULTS}

\section{Long DGCs lasting 1-3 h (large bursts)}

During the first two months of diapause (September and October) the pupae displayed the discontinuous gas exchange cycles (DGCs) with large bursts of carbon dioxide lasting 15-20 $\mathrm{min}$, while the length of the interburst periods was 8-23 h. However, during the next months the interburst periods became shorter.

The non-chilled four- and five-month-old diapausing pupae, kept at room temperature, displayed different, individually varying patterns of gas exchange. About $40 \%$ of the pupal individuals exhibited bursts with intervals of one to three hours, while a burst usually lasted 5-8 min (Figs 1-2). This type of carbon dioxide bursts is referred to as large bursts. The interburst periods of these pupae were characterised by the appearance of more or less regular spikes on the respirograms. The spikes were 


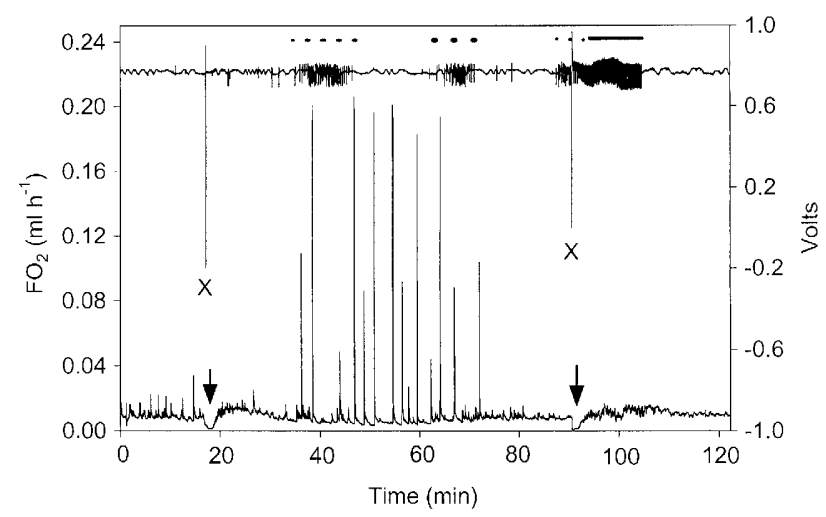

Fig. 1. The lower trace (left axis) represents a respirogram of a diapausing pupa of $P$. brassicae $(390 \mathrm{mg})$ with a long cycle of discontinuous gas exchange; bursts of carbon dioxide are indicated by arrows; the high spikes between the bursts are the passive suction inspirations (PSIs). The upper trace (right axis) denotes a simultaneous IR-recording, showing two strokes of abdominal swinging movements ("X") and heartbeats. Note that the abdominal movements coincide exactly with the beginning of bursts.

not caused by muscular contractions, as they were not reflected on the IR-recordings (Fig. 3). Visual observations of the ethanol meniscus in the glass capillary of the respirometer showed that the spikes were due to the rapid air intakes into the tracheae, or passive suction inspirations (PSIs) occurring during the interburst period. It was obvious that the higher was a PSI spike, the larger was the amount of the air sucked into the tracheae. During the interburst period, lasting about one hour, there occurred 8-12 PSIs. The intervals between the PSIs ranged from two to four minutes, and the frequency of PSIs was 4-6 per 10 min (Figs 1 and 3). The highest PSI spikes were observed in the middle section of the interburst period.

\section{Short DGCs lasting 2-5 min (small bursts)}

About $30 \%$ of the three- and four-month-old diapausing pupae displayed short gas exchange cycles with relatively small and frequent bursts of carbon dioxide. Small bursts lasted 1-2 min and were followed by intervals of 2-4 min (Figs 4 and 5). These pupae were characterised by frequent PSIs (2-6 per min) reflected on the respirograms as highly irregular short spikes, $4-8$ times shorter than those

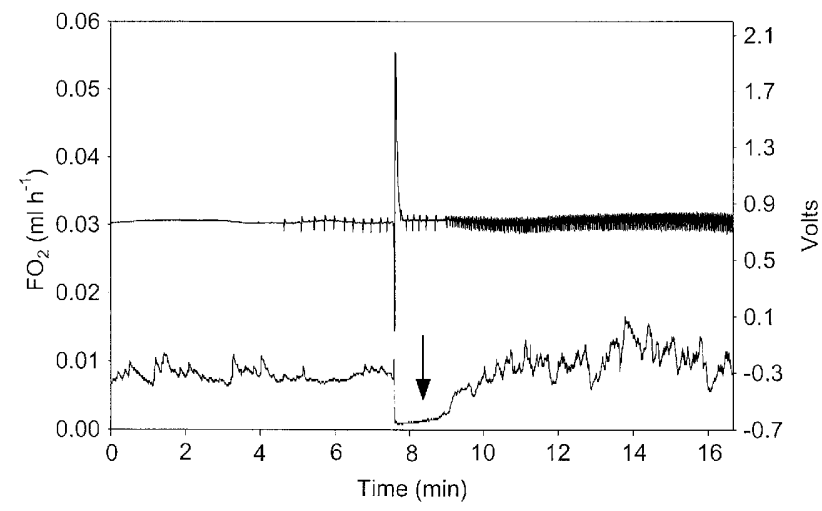

Fig. 2. A detail of Fig. 1 showing a burst (lower trace) and an abdominal swinging movement superimposed on the signals due to the heartbeats (upper trace).

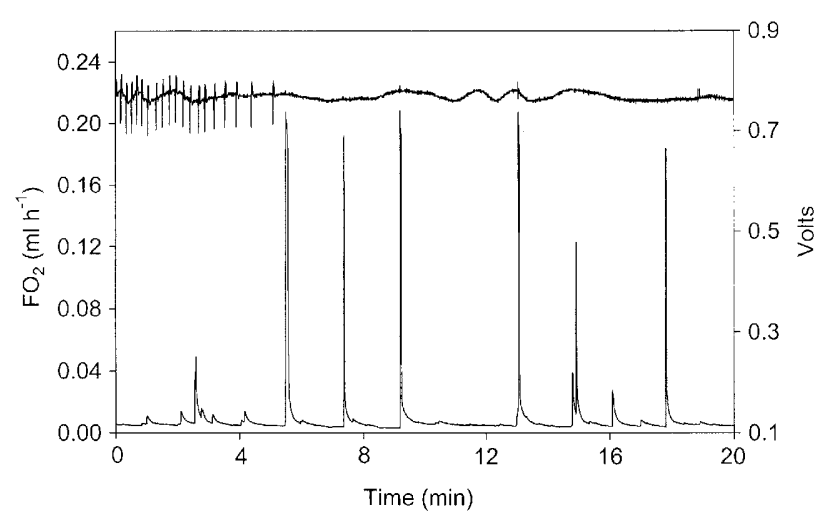

Fig. 3. A high resolution respirometric recording of PSIs (a detail of Fig. 1). Note that on the simultaneous IR-recording, no spikes due to muscular contractions are associated with single PSIs.

in the pupae with long cycles and large bursts (compare Figs 2 and 3).

\section{Obligatory abdominal movements}

A characteristic event in diapausing pupae was a vigorous stroke of the swinging (shaking) movement of the abdomen from one side to the other with maximum amplitude. Such a swinging movement of the abdomen (Figs 1 and 2) initiated about $80 \%$ of observed large bursts of carbon dioxide. The start of a burst coincided exactly with a stroke of swinging movement (Fig. 2). Hence it was concluded that the strokes of swinging movements were obligatory and not accidental stress signs. Small bursts with short interburst periods were not associated with the abdominal swinging movements; however, these bursts occurred at irregular intervals, usually $1-3$ strokes per hour.

\section{Standard metabolic rates, body mass loss and mortality of pupae}

Standard metabolic rate (SMR) during the first two months of diapause ranged from 18 to 26 (mean 22.5 \pm 4.3$) \mathrm{ml} \mathrm{O}_{2} \mathrm{~g}^{-1} \mathrm{~h}^{-1}$. Gradually, the SMR increased during the following three months about twice and remained on a stable level thereafter. The SMRs of the

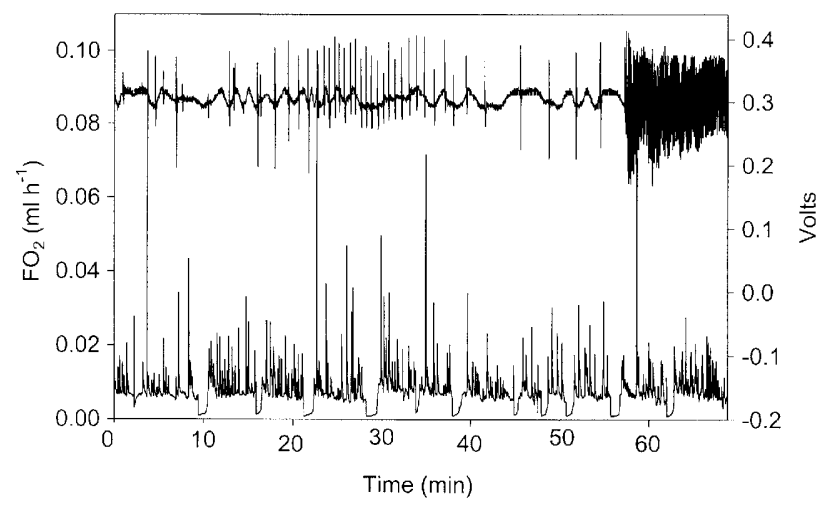

Fig. 4. A typical respirogram (lower trace, left axis) of short cycles and irregular microcycles between the bursts (downward peaks) from a diapausing pupa of $P$. brassicae $(345 \mathrm{mg})$. The upper trace denotes a synchronous IR-recording; the spikes are the heartbeats. 


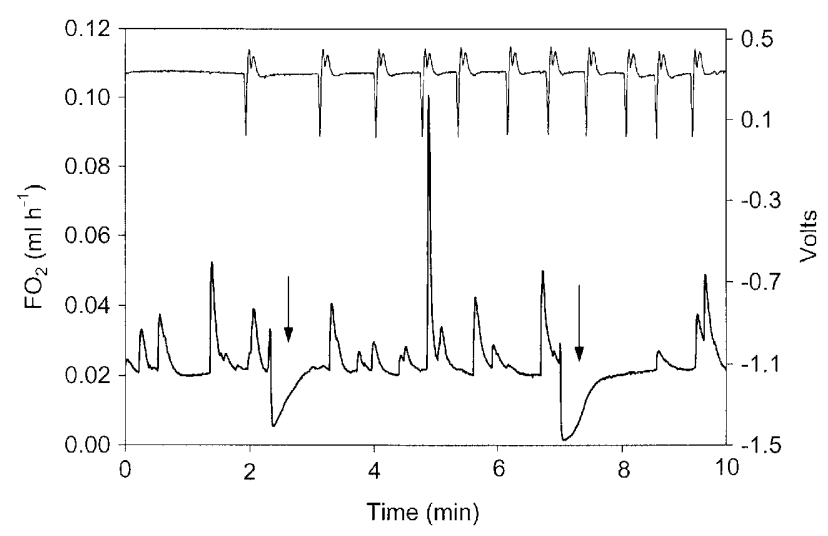

Fig. 5. A detailed pattern of short cycles and small bursts (arrows) in a diapausing pupa of $P$. brassicae. The spikes on the upper IR-recording form a typical pattern of heartbeats (systoles are directed downward).

pupae with long and short cycles were not significantly different, ranging from 28-61 (mean $44.95 \pm 5.3$ ) $\mathrm{ml} \mathrm{O}_{2}$ $\mathrm{g}^{-1} \mathrm{~h}^{-1}$ and from 32-56 (mean $47.6 \pm 4.6$ ) $\mathrm{ml} \mathrm{O}_{2} \mathrm{~g}^{-1} \mathrm{~h}^{-1}$, respectively (Student's t-test, $\mathrm{t}=-1.7, \mathrm{p}=0.09, \mathrm{~N}=20$ pupae of each group).

Body mass loss in the pupae with long and short cycles measured during November and December was $0.29 \pm$ $0.1 \mathrm{mg} \mathrm{g}^{-1} \mathrm{~h}^{-1}$ and $1.73 \pm 0.31 \mathrm{mg} \mathrm{g}^{-1} \mathrm{~h}^{-1}$, respectively. Thus body mass loss in the pupae with short cycles and small bursts was significantly greater than in the pupae showing long cycles and large bursts (Student's t-test, $\mathrm{t}=$ $-19.1 ; \mathrm{P}<0.001 ; \mathrm{N}=20$ pupae in each group).

After six months in diapause, mortality (in February), obviously due to desiccation, reached $80 \%$ in pupae $(\mathrm{N}=$ 35 ) that showed small and frequent bursts, while their body mass decreased about $30 \%$ of initial pupal mass. At the same time, mortality was not observed in the pupae $(\mathrm{N}=15)$ displaying long cycles. The SMR of the pupae never exceeded $80 \mathrm{ml} \mathrm{O}_{2} \mathrm{~g}^{-1} \mathrm{~h}^{-1}$ in either group, indicating that adult development had not yet begun.

\section{DISCUSSION}

After having been kept at room temperature for several months, the studied non-chilled diapausing pupae displayed patterns of gas exchange with high individual variation. These different patterns of gas exchange were obviously due to abnormal conditions - diapause in the non-chilled pupae at room temperature was prolonged over its natural end.

Pupal diapause usually terminates only after a prolonged exposure several weeks or months to relatively low temperatures $\left(<10^{\circ} \mathrm{C}\right)$ (Beck, 1968; Feltwell, 1982, Gardiner, 1985). When non-chilled P. brassicae diapausing pupae were kept at room temperature $\left(20-25^{\circ} \mathrm{C}\right)$ they did not initiate their adult development (Harak et al., 1999). However, spontaneous adult development has also been observed in some individuals of non-chilled diapausing lepidopteran pupae (Slama \& Neven, 2001).

We compared gas exchange and water loss in pupae of two extreme groups: individuals displaying long cycles of gas exchange and those characterised by short cycles. The main finding of the present paper was the existence of a relationship between the pattern of gas exchange and water loss in diapausing pupae of $P$. brassicae. Water loss was significantly greater in the pupae displaying short cycles of gas exchange and irregular and short microcycles than in the pupae with long cycles and regular but rare microcycles. Since SMR was not different for either group of pupae, we suggested that rare bursts and effective PSIs by themselves played a role in the water conserving mechanism in these pupae. Our results are in accordance with the theory that passive suction ventilation is an important water conserving mechanism (Kestler, 1980, 1982, 1985; Hadley, 1994a).

The pupae of $P$. brassicae were very susceptible to apparatus and handling stress despite their state of deep diapause and the low level of standard metabolic rate. During the first 2-6 h of measurement the cycles became longer until a stable rhythm was achieved. One could interpret the short cycles as evidence of stress due to "permanent" diapause in non-chilled pupae. However, as no increased muscular activity was detected during this presumable stress period, while SMR was not increased either, the "stress" was expressed only in the pattern of gas exchange.

According to our observations, there was no constriction, or the $\mathrm{C}$ phase, in the diapausing pupae of $P$. brassicae irrespective of the length of DGC immediately after burst spikes due to PSIs, were recorded on several devices. The "flutter" phase consisted of almost regular spikes due to PSIs. Slama (1999) already pointed out that in most lepidopteran pupae, the interburst period lacks the $\mathrm{C}$ phase altogether and that the $\mathrm{C}$ phase is characteristic only of large saturniid pupae.

The only obligatory active body movement that was established by us was the shaking of the abdomen from one side to the other. Most observed large burst of carbon dioxide was initiated by a shaking stroke. However, it is not excluded that very weak abdominal contractions occurred during the bursts, as the devices used did not record these. Extracardiac hemocoelic pulsations (EHPs) can be easily confused with heartbeats (Slama, 2000). In diapausing pupae of Manduca sexta, EHPs are lacking or occur only during the bursts (Slama \& Miller, 2001); the same may be also true for diapausing pupae of $P$. brassicae. The body stereotypic movements in lepidopteran pupae is not an exceptional event. Slama (1991) recorded regular twisting movements of the abdomen of Attacus atlantis (Lepidoptera, Saturniidae) in $100 \mathrm{~min}$ intervals. The regular abdominal rotations were observed in diapausing Cecropia pupae associated with brief outburst of intratracheal gases (Slama, 1988).

The pupae of $P$. brassicae displaying long DGC showed rare but deep inspiration movements during the interburst period. Frequent and weak inspirations were observed during interburst periods of short DGCs.

The passive oscillation in haemolymph pressure due to passive inspirations in a 30-day old diapausing pupa of $P$. brassicae was recorded by means of contact transducers from the tip of the abdomen and from the direct hydraulic 
transducer (Slama, 1984). The frequency of the mentioned inspirations was similar to that we recorded in $P$. brassicae displaying long DGCs.

The interrelations between gas exchange and heart activity in pupae of $P$. brassicae are of great interest. Some figures (Figs 1 and 2) show a clear coordination between the mentioned events: a trend of coincidence of the frequent heartbeats with the bursts; however this relationship deserves to be treated in a separate study (in prep.). The heartbeat reversal is a common event in lepidopteran pupae, and in some species the bursts coincide most frequently with forward pulsations of heart (Wasserthal, 1996; Hetz et al., 1999).

The obtained results allowed to conclude that the electrolytic respirometer, which may be considered "oldfashioned" today, enables the direct recording of discrete microcycles of gas exchange, the PSIs. Besides, the electrolytic respirometer can be easily combined with an infrared actographic device for the simultaneous recording of respiration and the muscular contractions occurring in the abdomen of pupae of $P$. brassicae.

ACKNOWLEDGEMENTS. We are much obliged to two anonymous reviewers for their important advice and comments on an earlier version of the manuscript. This research was supported by the Estonian Science Foundation Grants No 4993, 4116, 4105 and 5330.

\section{REFERENCES}

Beck S.D. 1968: Insect Photoperiodism. Academic Press, New York, London, $288 \mathrm{pp}$.

Chown S.L. 2002: Respiratory water loss in insects. Comp. Biochem. Physiol. (A) 133: 791-804.

Duncan F.D., Krasnov B. \& McMaster M. 2002: Novel case of a tenebrionid beetle using discontinuous gas exchange cycle when dehydrated. Physiol. Entomol. 27: 79-83.

Feltwell J. 1982: Large White Butterfly. The Biology, Biochemistry and Physiology of Pieris brassicae (Linnaeus). Dr. W. Junk Publishers, The Hague, Boston, London, 535 pp.

Gardiner B.O.C. 1985: Pieris brassicae. In Singh P. \& Moore R.F. (eds): Handbook of Insect Rearing. Vol. II. Elsevier, Amsterdam, Oxford, New York, Tokyo, 514 pp.

HADLEY N.F. 1994a: Ventilatory patterns and respiratory transpiration in adult terrestrial insects. Physiol. Zool. 67: $175-189$.

Hadley N.F. 1994b: Water Relations of Terrestrial Arthropods. Academic Press, San Diego, New York, Boston, London, Sydney, Tokyo, Toronto, $356 \mathrm{pp}$.

HADLEY N.F. \& QUINLAN M. 1993: Discontinuous carbon dioxide release in the eastern lubber grasshopper Romalea guttata and its effect on respiratory transpiration. J. Exp. Biol. 177: $169-180$.

Harak M., Lamprecht I., Kuusik A., Hitesaar K., Metspalu L. \& TARTES U. 1999: Calorimetric investigations of insect metabolism and development under the influence of a toxic plant extract. Thermochim. Acta 333: 39-48.

Hetz S.K. 1994: Untersuchungen zu Atmung, Kreislauf und Säure-Basen-Regulation an Puppen der Tropischen Schmetterlingsgattungen Ornithoptera, Troides und Attacus. Dissertation, University Erlangen-Nürnberg, Germany, 190 pp.

Hetz S.K., Psota E. \& Wasserthal L.T. 1999: Roles of aorta, ostia and tracheae in heartbeat and respiratory gas exchange in pupae of Troides rhadamantus Staudinger 1888 and Orni- thoptera priamus L. 1758 (Lepidoptera, Papilionidae). Int. J. Insect Morphol. Embryol. 28: 131-144.

Kestler P. 1980: Saugventilation verhindert bei Insekten die Wasserabgabe aus dem Tracheensystem. Verh. Dt. Zool. Ges. 1980: 306.

Kestler P. 1982: Wie verhindern Stigmen den Wasserverlust? Verh. Dt. Zool. Ges. 1982: 262.

KeStLER P. 1985: Respiration and respiratory water loss. In: Hoffmann K.H. (ed.): Environmental Physiology and Biochemistry of Insects. Springer, Berlin, pp. 137-183.

Kozhanchikov I.V. 1961: Study Methods in Insect Ecology. Vyshaya shkola, Moscow, 284 pp. (in Russian)

Kuusik A., Tartes U., Harak M., Hiesaar K. \& Metspalu L. 1994: Developmental changes during metamorphosis in Tenebrio molitor (Coleoptera: Tenebrionidae) studied by calorimetric thermography. Eur. J. Entomol. 91: 297-305.

Kuusik A., Harak M., Hitesaar K., Metspalu L. \& Tartes U. 1996: Different types of external gas exchange found in pupae of greater wax moth Galleria mellonella (Lepidoptera: Pyralidae). Eur. J. Entomol. 93: 23-35.

Kuusik A., Harak M., Hiiesaar K., Metspalu L. \& Tartes U. 1999: Studies on muscular activity, gas exchange cycles and water loss in pupae of great wax moth Galleria mellonella (Lepidoptera, Pyralidae) during physiological stress. Proc. XXIV Nordic Congr. Entomol. Tartu, 1997. pp. 77-82.

Kuusik A., Tartes U., Vanatoa A., Hitesaar K. \& Metspalu L. 2001: Body movements and their role as triggers of heartbeats in pupae of the Colorado potato beetle Leptinotarsa decemlineata Say. Physiol. Entomol. 26: 158-164.

Lighton J.R.B. 1994: Discontinuous ventilation in terrestial insects. Physiol. Zool. 67: 142-162.

Lighton J.R.B. 1998: Notes from under grown: towards ultimate hypotheses of cyclic, discontinuous gas exchange in tracheate arthropods. Am. Zool. 38: 483-491.

Machin J., Kestler P. \& Lampert G.J. 1991: Simultaneous measurements of spiracular and cuticular water losses in Periplaneta americana: implications for whole-animal mass loss studies. J. Exp. Biol. 161: 439-453.

Metspalu L., Kuusik A., Hilesaar K., Jõudu J., Tartes U. \& HARAK M. 2001: Simultaneous recording of gas exchange cyclicity, body movements and heartbeats in pupae of Leptinotarsa decemlineata Say made by infrared optical method. Norw. J. Entomol. 48: 91-96.

Metspalu L., Kuusik A., Hitesaar K. \& Tartes U. 2002: Tonic immobility in adult Colorado potato beetle, Leptinotarsa decemlineata (Coleoptera: Chrysomelidae) evoked by mechanical and optical stimuli. Eur. J. Entomol. 99: 215-219.

MiLL P.J. 1985: Structure and physiology of respiratory system. In Kerkut G.A. \& Gilbert L.J. (eds): Comprehensive Insect Physiology, Biochemistry and Pharmacology. Pergamon Press, Oxford, pp. 517-593.

MilLER P.L. 1974: Respiration - aerial gas transport. In Rockstein M. (ed.): The Physiology of Insecta. Vol. 6. Academic Press, New York, San Francisco, London, pp. 345-402.

MiLLER P.L. 1981: Ventilation in active and inactive insects. In: Herreid C.F. \& Fourtner C.R. (eds): Locomotion and Energetics in Arthropods. Plenum Press, New York, pp. 367-390.

SLAMA K. 1984: Recording of haemolymph pressure pulsations from the insect body surface. J. Comp. Physiol. 154: 635-643.

Slama K. 1988: A new look at insect respiration. Biol. Bull. Mar. Biol. Lab. Woods Hole 175: 289-300.

Slama K. 1991: Regulation of autonomic physiological functions in silkmoths. In Akai H. \& Kiuchi M. (eds): Wild Silkmoths 89'. 90'. Int. Soc. Wild Silkmoths, Tsukuba (Japan), pp. 107-119. 
Slama K. 1999: Active regulation of insect respiration. Ann. Entomol. Soc. Am. 92: 916-929.

Slama K. 2000: Extracardiac versus cardiac haemocoelic pulsation in pupae of the mealworm (Tenebrio molitor L.). $J$. Insect Physiol. 46: 977-992.

Slama K. \& Miller T.A. 2001: Physiology of heartbeat reversal in diapausing pupae of the tobacco hornworm, Manduca sexta (Lepidoptera: Sphingidae). Eur. J. Entomol. 98: 415-431.

Slama K. \& Neven L. 2001: Active regulation of respiration and circulation in pupae of the codling moth (Cydia pomonella). J. Insect Physiol. 47: 1321-1336.

TARTES U. \& KuUsiK A. 1994: Periodic muscular activity and its possible functions in pupae of Tenebrio molitor. Physiol. Entomol. 19: 216-222.
Tartes U., KunsiK A. \& Vanatoa A. 1999: Diversity in gas exchange and muscular activity patterns in insect studied by respirometer-actograph. Physiol. Entomol. 24: 150-157.

Tartes U., Vanatoa A. \& KuUsiK A. 2002: The insect abdomen - a heartbeat manager in insects? Comp. Biochem. Physiol. (A) 133: 611-623.

WASSERTHAL L.T. 1996: Interaction of circulation and tracheal ventilation in holometabolous insects. Adv. Insect Physiol. 26: 297-351.

Withers P.C. 1992: Comparative Animal Physiology. Saunders College, Fort Worth, 949 pp.

Received August 22, 2003; revised December 1, 2003; accepted March 10, 2004 